\title{
Correlates of adiposity in a Caribbean pre-school population
}

\author{
Anisa Ramcharitar-Bourne ${ }^{1, *}$, Selby Nichols ${ }^{1}$ and Neela Badrie ${ }^{2}$ \\ ${ }^{1}$ Department of Agricultural Economics and Extension, The University of the West Indies, St. Augustine, \\ Trinidad and Tobago: ${ }^{2}$ Department of Food Production, The University of the West Indies, St. Augustine, \\ Trinidad and Tobago
}

Submitted 21 August 2012: Final revision received 1 May 2013: Accepted 13 June 2013: First published online 18 July 2013

\begin{abstract}
Objective: To evaluate ethnic and anthropometric correlates of adiposity among a nationally representative, multi-ethnic, Trinidadian pre-school population. Design: Cross-sectional study conducted between June 2008 and July 2009. Setting: Government and privately owned Early Childhood Care and Education Centres in Trinidad.

Subjects: A total of 596 pre-school children (aged 31-73 months) from thirty-four schools had their weight, height, mid-upper arm circumference, waist circumference, biceps and triceps skinfold thicknesses measured by a registered dietitian using standard procedures. Percentage body fat was estimated using a foot-to-foot bioelectric impedance analyser (Tanita 531, Tokyo, Japan). Date of birth, religion and ethnicity were extracted from school records and pre-schoolers' ethnicity was categorized as East Indian, African, Mixed (a combination of two or more ethnicities), Chinese or Caucasian.

Results: Anthropometric variables explained significantly more of the variance in adiposity among girls $(67 \cdot 4-88 \cdot 1 \%)$ than boys $(24 \cdot 4-39 \cdot 2 \% ; P<0 \cdot 001)$. Pre-schoolers of African descent were significantly taller, heavier and had higher abdominal fat and mid-upper arm circumference than their East Indian and Mixed counterparts (all $P<0 \cdot 001$ ). The overall prevalence of excess adiposity ( $\geq 25 \%$ body fat) as determined by bioelectrical impedance was $14.6 \%$, while $2.9 \%$ of the children were undernourished according to WHO weight-for-age criteria. Differences in anthropometry were non-existent between children attending government and private pre-schools.

Conclusions: Gender, ethnicity and anthropometry all explained excess adiposity in these pre-schoolers. These findings highlight the need to elucidate the mechanisms that may be involved in explaining these differences, particularly those of ethnic origin.
\end{abstract}

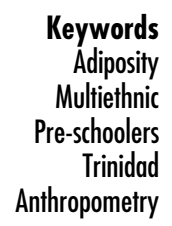

Nutrition-related chronic non-communicable diseases are a major cause of illness and death among adults in the Caribbean ${ }^{(1)}$ and have become a major public health challenge among Caribbean governments. The alacrity of the change from infectious to non-communicable diseases has left many countries in the region having to address simultaneously health issues associated with over- and undernutrition $^{(2)}$. This change has paralleled the nutritional transition with improvements in socioeconomic status of the region in the post-colonial era. During this period, diets changed from those where nutrients were derived from unrefined plant foods to diets where the main nutrients come from foods high in refined sugars, fats and salt ${ }^{(3)}$. Epidemiological analyses have shown several linkages between consumption of refined plant grains and fats and the obesity epidemic ${ }^{(4)}$. Moreover, occupations have changed from those that were labour intensive to those that were better paying but primarily sedentary in nature. The result of these activities reduced energy expenditure while increasing energy intakes, with a concomitant increase in body weight and the prevalence of obesity ${ }^{(5)}$. For many of these chronic noncommunicable diseases, overweight and obesity appear to be consistent and important risk factors ${ }^{(6)}$.

These chronic non-communicable diseases seem to have their genesis very early in life ${ }^{(7)}$, with hypertension, hyperlipidaemia, insulin resistance and diabetes mellitus being apparent in the child and adolescent population globally ${ }^{(8)}$. Similar to the situation among adults, these diseases seem to be driven by childhood and adolescent overweight and obesity ${ }^{(9)}$. In May 2004, the International Obesity Taskforce (IOTF) of the WHO, in collaboration with the International Association for the Study of Obesity, issued a report that indicated at least 155 million 
school-aged children worldwide to be overweight or obese, with $2-3 \%$ of them being classified as obese. A further 22 million children under the age of 5 years, which includes the pre-school age, are also affected ${ }^{(10)}$. Martorell et al. in $2000^{(11)}$ reported the prevalence of obesity in Caribbean pre-schoolers to be as high as that found in the USA. This rise in childhood obesity is probably the most worrying aspect of the obesity epidemic ${ }^{(12)}$. Given these trends, it is surprising to find a paucity of published studies documenting the obesity epidemic in the region ${ }^{(13)}$. The pre-school years are formative years in a child's life, where children develop healthful eating habits essential for normal growth and the prevention of nutrition-related diseases later in life ${ }^{(14)}$. The present study therefore sought to investigate the prevalence of excess adiposity, as well as to evaluate the anthropometric and ethnic correlates of adiposity, in a multi-ethnic Trinidadian preschool population. The importance of defining the extent of adiposity in children from different ethnic groups has been documented in the literature ${ }^{(15)}$. The findings from the present study would provide a base from which to inform public policy and develop appropriate and tailored interventions specific to this population.

\section{Experimental methods}

\section{Design}

The ethnic make-up of Trinidad and Tobago is reflected by its historical background. Of the 1.3 million inhabitants residing in Trinidad and Tobago, there are two major ethnic groups. The Indo- and Afro-Trinidadians and the Tobagonians each make up about $40 \%$ of the population, while people of Mixed descent make up just over $16 \%$. The remainder is accounted for mainly by the Whites and Chinese ${ }^{(16)}$. In the present cross-sectional study, seventeen Government Early Childhood Care and Education Centres were randomly selected from all seven educational districts in Trinidad, namely: St. George East, North Eastern, Victoria, South Eastern, Caroni, Port of Spain \& Environs, and St. Patrick. Although schools were not selected based on a socio-economic basis, each of the seventeen public schools was matched to its nearest privately owned Early Childhood Care and Education Centre, giving a total of thirty-four participating schools. Private schools require that parents pay for the child's education, while public schools are free. The sampling frame was obtained from the Ministry of Education, Trinidad and Tobago website ${ }^{(17)}$. This represented approximately $11 \%$ of the sampling frame for Government schools. Prior to commencement of the study, permission was obtained from both the Early Childhood Care and Education Centre Unit of the Ministry of Education, Trinidad and Tobago and the principals of the selected schools. Parents were asked to complete a consent form to demonstrate their willingness to have their child participate in the study. Only those pupils whose parents gave written consent were enrolled in the study. There was a response rate of $43.7 \%$ and a participation rate of $90 \%$.

\section{Participants and antbropometry}

A total of 596 children with ages ranging from 31 to 73 months were measured by a registered dietitian, who also served as the Principal Investigator. Standardized approved protocols were used throughout the investigation $^{(18)}$. All measurements were taken at the respective schools with children in school uniforms and barefoot, with pocket contents removed. Measurements were done during the morning period between 08.30 and 11.30 hours from June 2008 to July 2009. Height was measured to the nearest millimetre using a Seca stadiometer (model 214; Seca Corp., Hanover, MD, USA) with participants standing on a horizontal surface with their bodies stretched upward to the fullest extension and their heads in the Frankfort plane ${ }^{(19)}$. Hair ornaments were removed prior to height measurements among female pre-schoolers.

Body weight was recorded to the nearest $0.1 \mathrm{~kg}$ and body fat was recorded to the nearest $0.5 \%$ using a Tanita foot-to-foot bioelectric impedance device (model 531; Tanita Corp., Tokyo, Japan). This device required participants to stand on the foot pad electrodes of the machine for measurements ${ }^{(20)}$. Body fat estimates from this device show high levels of correlation $(r>0 \cdot 8)$ with percentage body fat $(\% \mathrm{BF})$ estimated by conventional bioelectric impedance and dual-energy X-ray absorptiometry ${ }^{(21,22)}$. Foot-to-foot bioelectric impedance may under- or overestimate adiposity depending on the size and gender of the individuals being measured and is therefore more suitable for estimating adiposity in groups rather than in individuals ${ }^{(23-25)}$.

A flexible, non-stretchable tape measure was used for measuring body circumferences. Waist circumference (WC) was measured at the level of the umbilicus with the tape measure placed in a horizontal plane against the bare skin. Triceps skinfold thickness (TSF), biceps skinfold thickness (BSF) and mid-upper arm circumference (MUAC) were taken on the right side of the child's body with the use of a plastic 'Slim Guide' skinfold calliper. Biceps and triceps measurements were done in triplicate to the nearest $0.2 \mathrm{~mm}$ or until the variation in consecutive measurements was less than $1 \mathrm{~mm}$. Gender, date of birth, religion and ethnicity were also recorded. Ethnicity was categorized as East Indian, African, Mixed, Chinese or Caucasian.

BMI was calculated as weight in kilograms divided by the square of height in metres $\left(\mathrm{kg} / \mathrm{m}^{2}\right)$. The WHO Anthro calculator version $3 \cdot 2 \cdot 2$ and Anthro Plus $1 \cdot 0 \cdot 4$ software were used to calculate percentiles and $Z$-scores for weight-for-age, BMI-for-age, MUAC-for-age and TSFfor-age. Overweight and obesity were defined according to the recommendations suggested by the IOTF, using the international standard definition by Cole et $a l^{(26)}$ (2000), as well as by the US Centres for Disease Control and Prevention (CDC) $)^{(27)}$ (2010). 
A cut-point of $\geq 25 \%$ body fat as determined by bioelectrical impedance was used to define excess adiposity in this population. This is in accordance with Taylor et al., who reported a $24-30 \%$ body fat that coincided with an obese BMI in younger boys and a similar \%BF in young girls ${ }^{(28,29)}$.

\section{Statistical analysis}

All statistical analyses were conducted using the statistical software package SPSS version 15 for Windows. Results were expressed as means and standard deviations or as percentages. Kolmogorov-Smirnov tests for normality were performed on all variables prior to analysis. Continuous variables that were non-normal were log transformed. Parametric tests were performed on the log-transformed variables, while non-parametric versions were done on the untransformed variables; for example, the independentsamples $t$ test was used to determine gender differences in log-transformed BMI, while the Mann-Whitney $U$ test was used to evaluate gender differences in the untransformed BMI. Similarly, the Kruskal-Wallis test and ANOVA were used to evaluate ethnic differences in the untransformed and log-transformed continuous variables, respectively. Levene's test was done to test for equality of variances, while the $\chi^{2}$ test analysed the association of excess adiposity for categorical variables. Post hoc procedures (Bonferroni and Tukey tests) were used to determine which groups had significant differences in anthropometric and body composition measures by ethnicity. Both simple and multiple linear regression analyses were used to determine the variance in adiposity as explained by the anthropometric variables.

\section{Results}

\section{General characteristics of participants}

The proportion of boys ( $n$ 301, 50.5\%) and girls ( $n$ 295, $49.5 \%)$ in the study was similar, and their mean ages were
53.6 (sD 7.41) months and 52.9 (sD 6.97) months, respectively. Children of African descent accounted for $31 \cdot 2 \%$ of the sample ( $n$ 186), while there were $43.6 \%$ children of East Indian descent ( $n$ 260) and $24 \cdot 0 \%$ Mixed ( $n$ 143). Pre-schoolers of Caucasian and Chinese descent made up the remaining $1 \cdot 2 \%$ of the sample and were not used in further analyses. There were no significant differences in religion by gender, with Christians making up over half of the study population. This was followed by Hindus ( $25 \%$ ), then 'undeclared' (those who did not declare a religion; $11 \cdot 6 \%$ ) and Muslims (8.9\%). Approximately $55 \%$ of the pre-schoolers attended government schools, while the remainder went to private schools. There were no significant differences in anthropometry between children attending private and public schools, hence both groups were analysed together.

\section{Antbropometric characteristics and correlates of adiposity}

Boys were significantly taller $(P=0 \cdot 038)$, heavier $(P=0 \cdot 009)$, had higher WC $(P=0 \cdot 016)$ and higher \%BF $(P<0.001)$ as obtained by bioelectrical impedance analysis than girls, while girls displayed significantly higher TSF and BSF (both $P<0.001$ ) than boys. The prevalence of excess adiposity ( $\geq 25 \%$ body fat) as determined by bioelectrical impedance analysis was $12 \cdot 2 \%$ for boys and $5 \cdot 1 \%$ for girls $\left(\chi^{2}(1)=9 \cdot 468, P=0 \cdot 002\right.$; Table 1$)$. Table 2 shows the anthropometric characteristics by ethnic group. Pre-schoolers of African descent were significantly taller $(P<0.001)$ and heavier $(P<0.001)$ than those of East Indian and Mixed descent, respectively. They also had significantly higher BMI $(P<0.001)$, WC $(P<0.001)$ and MUAC $(P<0.001)$ than their East Indian and Mixed descent counterparts. On the other hand, pre-schoolers of East Indian descent possessed significantly higher TSF $(P=0 \cdot 026)$ than their Mixed counterparts. Although Mixed pre-schoolers were significantly younger than their African

Table 1 Anthropometric characteristics of participants by gender: nationally representative sample of pre-school children aged 31-73 months ( $n$ 596), Trinidad, June 2008 to July 2009

\begin{tabular}{|c|c|c|c|c|c|}
\hline \multirow[b]{2}{*}{ Anthropometric characteristic } & \multicolumn{2}{|c|}{ Boys ( $n$ 301) } & \multicolumn{2}{|c|}{ Girls (n 295) } & \multirow[b]{2}{*}{ Mann-Whitney $P$ value } \\
\hline & Mean & SD & Mean & SD & \\
\hline Age (months) & $53 \cdot 58$ & $7 \cdot 41$ & $52 \cdot 94$ & $6 \cdot 97$ & 0.258 \\
\hline Height $(\mathrm{cm})$ & $107 \cdot 03$ & $8 \cdot 47$ & $105 \cdot 79$ & $5 \cdot 82$ & $0.038^{\star}, t$ \\
\hline Weight (kg) & $18 \cdot 03$ & 3.94 & $17 \cdot 38$ & 3.94 & $0.009^{\star \star}$ \\
\hline $\operatorname{BMI}\left(\mathrm{kg} / \mathrm{m}^{2}\right)$ & $15 \cdot 51$ & $2 \cdot 25$ & $15 \cdot 39$ & $2 \cdot 28$ & 0.295 \\
\hline$\%$ BF using $\mathrm{BIA}$ & $19 \cdot 02$ & $5 \cdot 79$ & $14 \cdot 51$ & $5 \cdot 92$ & $<0.001^{\star *}$ \\
\hline WC $(\mathrm{cm})$ & $50 \cdot 93$ & $5 \cdot 54$ & $50 \cdot 23$ & $5 \cdot 89$ & $0.016^{*}$ \\
\hline MUAC $(\mathrm{cm})$ & $16 \cdot 82$ & $2 \cdot 06$ & $16 \cdot 77$ & $2 \cdot 02$ & 0.601 \\
\hline TSF $(\mathrm{mm})$ & $7 \cdot 26$ & $2 \cdot 52$ & 7.92 & $2 \cdot 83$ & $<0.001^{\star *}$ \\
\hline $\mathrm{BSF}(\mathrm{mm})$ & $4 \cdot 34$ & 1.56 & $4 \cdot 68$ & 1.73 & $<0.001^{\star *}$ \\
\hline BMI-for-age Z-score & 0.02 & 1.57 & -0.05 & $1 \cdot 36$ & 0.577 \\
\hline MUAC-for-age Z-score & 0.24 & $1 \cdot 28$ & $0 \cdot 15$ & $1 \cdot 19$ & 0.266 \\
\hline TSF-for-aqe Z-score & -0.45 & $1 \cdot 17$ & -0.50 & $1 \cdot 13$ & 0.208 \\
\hline
\end{tabular}

\%BF, percentage body fat; BIA, bioelectrical impedance analysis; WC, waist circumference; MUAC, mid-upper arm circumference; TSF, triceps skinfold thickness; BSF, biceps skinfold thickness.

${ }^{\star}$ Significance at the 0.05 level, ${ }^{\star *}$ significance at the 0.001 level.

tThe $P$ value reported for height was obtained from the independent-samples $t$ test, since height was normally distributed. 
Table 2 Anthropometric characteristics of participants by ethnicity: nationally representative sample of pre-school children aged 31-73 months ( $n$ 596), Trinidad, June 2008 to July 2009

\begin{tabular}{|c|c|c|c|c|c|c|c|c|}
\hline \multirow[b]{2}{*}{ Anthropometric characteristic } & \multicolumn{2}{|c|}{$\begin{array}{l}\text { East Indian (E) } \\
\quad(n \text { 260) }\end{array}$} & \multicolumn{2}{|c|}{$\begin{array}{l}\text { African (A) } \\
\quad(n 186)\end{array}$} & \multicolumn{2}{|c|}{$\begin{array}{l}\text { Mixed (M) } \\
(n \text { 143) }\end{array}$} & \multirow[b]{2}{*}{ Kruskal-Wallis $P$ value } & \multirow[b]{2}{*}{ Tukey/Bonferroni } \\
\hline & Mean & SD & Mean & SD & Mean & SD & & \\
\hline Male:female & \multicolumn{2}{|c|}{$137: 123$} & \multicolumn{2}{|c|}{ 92:94 } & \multicolumn{2}{|c|}{$68: 75$} & & \\
\hline Age (months) & $53 \cdot 63$ & $6 \cdot 59$ & $54 \cdot 08$ & $7 \cdot 52$ & $51 \cdot 52$ & $7 \cdot 64$ & 0.005 & $\mathrm{~A}=\mathrm{E}>\mathrm{M}$ \\
\hline Height $(\mathrm{cm})$ & $105 \cdot 95$ & $5 \cdot 78$ & $107 \cdot 99$ & $9 \cdot 52$ & $105 \cdot 37$ & $6 \cdot 16$ & $<0.001$ & $A>E=M$ \\
\hline Weight (kg) & $17 \cdot 22$ & $4 \cdot 08$ & 18.97 & $4 \cdot 04$ & $17 \cdot 01$ & $3 \cdot 16$ & $<0.001$ & $A>E=M$ \\
\hline $\mathrm{BMI}\left(\mathrm{kg} / \mathrm{m}^{2}\right)$ & $15 \cdot 21$ & $2 \cdot 57$ & $15 \cdot 95$ & $2 \cdot 13$ & $15 \cdot 23$ & $1 \cdot 71$ & $<0.001$ & $\mathrm{~A}>\overline{\mathrm{E}}=\mathrm{M}$ \\
\hline$\% B F$ using $\mathrm{BIA}$ & $17 \cdot 26$ & $7 \cdot 11$ & $16 \cdot 93$ & $6 \cdot 02$ & $15 \cdot 73$ & $4 \cdot 89$ & 0.091 & $\mathrm{~A}=\mathrm{E}=\mathrm{M}$ \\
\hline WC $(\mathrm{cm})$ & $50 \cdot 31$ & $6 \cdot 39$ & $51 \cdot 61$ & $5 \cdot 59$ & $49 \cdot 70$ & $4 \cdot 40$ & $<0.001$ & $A>E=M$ \\
\hline MUAC $(\mathrm{cm})$ & $16 \cdot 66$ & $2 \cdot 25$ & $17 \cdot 25$ & 2.03 & $16 \cdot 47$ & 1.53 & $<0.001$ & $A>E=M$ \\
\hline MUAC-for-age $Z$-score & $0 \cdot 10$ & $1 \cdot 36$ & 0.46 & $1 \cdot 24$ & 0.05 & 0.97 & $<0.001$ & $A>E=M$ \\
\hline $\mathrm{TSF}(\mathrm{mm})$ & $7 \cdot 85$ & $2 \cdot 97$ & $7 \cdot 62$ & $2 \cdot 86$ & $7 \cdot 05$ & $1 \cdot 79$ & 0.026 & $\mathrm{E}>\mathrm{M}=\mathrm{A}$ \\
\hline TSF-for-age $Z$-score & -0.36 & $1 \cdot 18$ & -0.48 & $1 \cdot 22$ & -0.67 & 0.97 & 0.092 & $E=M=A$ \\
\hline $\mathrm{BSF}(\mathrm{mm})$ & $4 \cdot 67$ & 1.90 & $4 \cdot 48$ & $1 \cdot 60$ & $4 \cdot 24$ & $1 \cdot 18$ & 0.092 & $\mathrm{E}=\mathrm{M}=\mathrm{A}$ \\
\hline BMI-for-age Z-score & -0.23 & 1.66 & 0.38 & $1 \cdot 34$ & -0.14 & $1 \cdot 15$ & $<0.001$ & $A>E=M$ \\
\hline
\end{tabular}

\%BF, percentage body fat; BIA, bioelectrical impedance analysis; WC, waist circumference; MUAC, mid-upper arm circumference; TSF, triceps skinfold thickness; BSF, biceps skinfold thickness.

Table 3 Prevalence of overweight and obesity by BMI classification system and gender: nationally representative sample of pre-school children aged 31-73 months ( $n$ 596), Trinidad, June 2008 to July 2009

\begin{tabular}{lcclccc}
\hline & \multicolumn{2}{c}{ IOTF classification ${ }^{(26)}$} & & \multicolumn{2}{c}{ CDC classification ${ }^{(27)}$} \\
\cline { 2 - 3 } \cline { 5 - 6 } \cline { 5 - 6 } & Boys (\%) & Girls (\%) & & Boys (\%) & Girls (\%) \\
\hline Overweight & 9.3 & 8.5 & & $7 \cdot 3$ & 8.8 \\
Obesity & 4.7 & 6.8 & & 12.3 & 8.8 \\
\hline
\end{tabular}

IOTF, International Obesity Taskforce; CDC, Centers for Disease Control and Prevention.

and East Indian counterparts $(P=0 \cdot 005)$, this age difference was negated by using BMI $Z$-scores adjusted for age.

Among boys, the overall prevalence of overweight and obesity using the IOTF criteria was $9 \cdot 3 \%$ and $4.7 \%$, respectively, while $8.5 \%$ and $6.8 \%$ of girls were overweight and obese. The CDC criteria identified a lower percentage of boys as overweight $(7 \cdot 3 \%)$ but almost tripled the prevalence of obese boys $(12 \cdot 3 \%)$ when compared with the IOTF cut-off. It also identified $8 \cdot 8 \%$ of girls as overweight and $8 \cdot 8 \%$ as obese (Table 3). Approximately $2.9 \%$ of children were classified as undernourished by the WHO criterion of weight-for-age $Z$-score $<-2$. On comparing ethnicities, although more African children were overweight and obese with the IOTF and CDC criteria, significant differences in prevalence were observed with the CDC criteria only, with $11.9 \%$ of Mixed and $17 \cdot 7 \%$ of East Indian pre-schoolers being overweight and obese compared with $25.3 \%$ of African pre-schoolers $(P=0 \cdot 007$; Table 4).

Table 5 shows the percentage variance in adiposity explained by each anthropometric variable by gender. Weight, BMI, WC and MUAC explained $78.9 \%, 87 \cdot 3 \%$, $83.2 \%$ and $83.1 \%$ of the variance in adiposity among females, while in males these variables accounted for $23 \cdot 9 \%, 30 \cdot 5 \%, 32 \cdot 3 \%$ and $30 \cdot 3 \%$, respectively. In boys,
TSF and BSF each accounted for $39 \cdot 2 \%$ and $32 \cdot 0 \%$ of the variance in adiposity, while in girls they explained over $55 \%$. While many indices worked well in explaining excess adiposity in girls, TSF performed best in boys. Within each ethnic group, the percentage variance in adiposity explained was also higher in girls as compared with boys. The percentage variance in adiposity explained by the various anthropometric measures tended to be highest for boys of African descent, compared with boys of other ethnicities (Table 6).

\section{Discussion}

The present study evaluated the prevalence of excess adiposity, as well as the ability of various anthropometric indices (weight, height, MUAC, WC, TSF, BSF and \%BF by bioelectrical impedance) to explain adiposity, in a multiethnic pre-school Trinidadian population. The choice of cut-off of $25 \%$ body fat used here is in accordance with Taylor et al., who reported a $24-30 \%$ body fat that coincided with an obese BMI in younger boys and a similar \%BF in young girls ${ }^{(28,29)}$. Our findings suggest that in this pre-school population there were gender differences in the ability of anthropometry to explain adiposity. In particular, anthropometric variables explained more of the variation in adiposity among females as compared with males ${ }^{(28,30,31)}$. This may be an indication of differences in location of body fat between males and females. Although boys presented with a higher overall total body fat, they had a larger WC, but lower TSF and BSF. The larger WC may imply a greater percentage of visceral fat, while the lower TSF and BSF may point to less fat accumulation in the upper peripheral regions of the body. In addition, the bioelectrical impedance analysis device measured total overall fat and not body fat by 
Table 4 Prevalence of overweight and obesity by BMI classification system and ethnicity: nationally representative sample of pre-school children aged 31-73 months ( $n$ 596), Trinidad, June 2008 to July 2009

\begin{tabular}{lccccc}
\hline Classification system & East Indian (E) (\%) & African (A) (\%) & Mixed (M) (\%) & $\chi^{2} P$ value & Tukey/Bonferroni \\
\hline CDC $^{(27)}$ & 17.7 & 25.3 & 11.9 & 0.007 & $A>M, E=A$ \\
IOTF $^{(26)}$ & 15.4 & 18.3 & 9.1 & 0.062 & $E=A=M$ \\
\hline
\end{tabular}

CDC, Centers for Disease Control and Prevention; IOTF, International Obesity Taskforce.

Table 5 Univariate anthropometric correlates of excess adiposity by gender: nationally representative sample of pre-school children aged 31-73 months ( $n$ 596), Trinidad, June 2008 to July 2009

\begin{tabular}{|c|c|c|c|c|}
\hline \multirow[b]{2}{*}{ Variable } & \multicolumn{2}{|c|}{$\%$ of variation explained $\left(R^{2}\right)$} & \multicolumn{2}{|c|}{$P$ value } \\
\hline & Boys & Girls & Boys & Girls \\
\hline Weight (kg) & $23 \cdot 9$ & $78 \cdot 9$ & $<0.001$ & $<0.001$ \\
\hline Height (cm) & $2 \cdot 7$ & $22 \cdot 0$ & $<0.05$ & $<0.001$ \\
\hline BMI $\left(\mathrm{kg} / \mathrm{m}^{2}\right)$ & $30 \cdot 5$ & $87 \cdot 3$ & $<0.001$ & $<0.001$ \\
\hline WC $(\mathrm{cm})$ & $32 \cdot 2$ & $83 \cdot 2$ & $<0.001$ & $<0.001$ \\
\hline MUAC $(\mathrm{cm})$ & $30 \cdot 3$ & $83 \cdot 1$ & $<0.001$ & $<0.001$ \\
\hline TSF (mm) & $39 \cdot 2$ & $67 \cdot 4$ & $<0.001$ & $<0.001$ \\
\hline $\mathrm{BSF}(\mathrm{mm})$ & $32 \cdot 0$ & $56 \cdot 0$ & $<0.001$ & $<0.001$ \\
\hline MUAC-for-age Z-score & $25 \cdot 1$ & $78 \cdot 9$ & $<0.001$ & $<0.001$ \\
\hline TSF-for-age Z-score & $25 \cdot 4$ & $55 \cdot 9$ & $<0.001$ & $<0.001$ \\
\hline BMI-for-age Z-score & $26 \cdot 3$ & $86 \cdot 1$ & $<0.001$ & $<0.001$ \\
\hline
\end{tabular}

$R^{2}$, coefficient of determination; WC, waist circumference; MUAC, mid-upper arm circumference; TSF, triceps skinfold thickness; BSF, biceps skinfold thickness.

Table 6 Univariate anthropometric correlates of excess adiposity by ethnicity: nationally representative sample of pre-school children aged 31-73 months ( $n$ 596), Trinidad, June 2008 to July 2009

\begin{tabular}{|c|c|c|c|c|c|c|c|}
\hline \multirow[b]{3}{*}{ Variable } & \multicolumn{6}{|c|}{$\%$ of variation explained $\left(R^{2}\right)$} & \multirow[b]{3}{*}{$P$ value } \\
\hline & \multicolumn{2}{|c|}{ East Indian } & \multicolumn{2}{|c|}{ African } & \multicolumn{2}{|c|}{ Mixed } & \\
\hline & Boys & Girls & Boys & Girls & Boys & Girls & \\
\hline Weight (kg) & $27 \cdot 0$ & $83 \cdot 8$ & $35 \cdot 0$ & $72 \cdot 2$ & $10 \cdot 4$ & $76 \cdot 8$ & $<0.001$ \\
\hline Height (cm) & $1 \cdot 3$ & $27 \cdot 5$ & $8 \cdot 3$ & $15 \cdot 1$ & $1 \cdot 0$ & $21 \cdot 5$ & $<0.001$ \\
\hline BMI $\left(\mathrm{kg} / \mathrm{m}^{2}\right)$ & $35 \cdot 4$ & $87 \cdot 9$ & $38 \cdot 2$ & $90 \cdot 4$ & $15 \cdot 1$ & $82 \cdot 6$ & $<0.001$ \\
\hline$W C(\mathrm{~cm})$ & $31 \cdot 6$ & $82 \cdot 7$ & $44 \cdot 4$ & 84.9 & $17 \cdot 2$ & $83 \cdot 3$ & $<0.001$ \\
\hline MUAC $(\mathrm{cm})$ & 34.5 & $84 \cdot 3$ & $36 \cdot 0$ & $82 \cdot 6$ & $19 \cdot 0$ & $80 \cdot 6$ & $<0.001$ \\
\hline TSF (mm) & $32 \cdot 7$ & $69 \cdot 7$ & $49 \cdot 5$ & $74 \cdot 2$ & $34 \cdot 4$ & $63 \cdot 1$ & $<0.001$ \\
\hline $\mathrm{BSF}(\mathrm{mm})$ & $26 \cdot 6$ & $62 \cdot 2$ & $45 \cdot 7$ & $61 \cdot \overline{1}$ & $24 \cdot 8$ & 38.5 & $<0.001$ \\
\hline
\end{tabular}

$R^{2}$, coefficient of determination; WC, waist circumference; MUAC, mid-upper arm circumference; TSF, triceps skinfold thickness; BSF, biceps skinfold thickness.

segment. The body fat locations in female pre-schoolers may also have had a stronger association with the anthropometric variables of interest in the present study, leading to a higher percentage of variation in adiposity being accounted for. Future research should therefore seek to highlight alternative indices that will explain more of the variation in adiposity among male pre-schoolers.

This higher level of adiposity among pre-school males has been demonstrated in other studies ${ }^{(32-36)}$. It may be linked to the higher consumption of energy-dense foods and increased sedentary activity ${ }^{(37-40)}$ among males in this age group. Growing evidence suggests that overweight and obesity are socially patterned ${ }^{(41,42)}$ and may also be linked to the cultural environment ${ }^{(43,44)}$ and cultural practice of food distribution and consumption within households locally ${ }^{(45)}$. In fact, our report of dietary intakes in this population suggests that more girls consumed fruit and vegetables at least five times per week, while twice as many boys were in the highest tertile for soda and fizzy beverage consumption (A Ramcharitar-Bourne, unpublished results). Furthermore, more girls than boys ate meals together with their families every day $(41 \cdot 2 \% v .26 \cdot 9 \%)$ and family meals have been identified as a protective factor against obesity among youth ${ }^{(46)}$. Regarding hours of television viewing, more girls met the American Academy of Pediatrics recommendations for total media time to be limited to less than $2 \mathrm{~h} / \mathrm{d}$ in children aged 2 years and older ${ }^{(47)}$. Only $3.8 \%$ of boys met this recommendation on the weekend as compared with $14 \cdot 7 \%$ of girls. Our finding suggests that Trinidadian pre-school children, especially boys, may be highly susceptible to obesity and to the early adoption of obesogenic lifestyles ${ }^{(38)}$. 


\section{Adiposity by classification system}

The prevalence of adiposity varied by classification system $^{(48)}$ with the BMI-based CDC criteria identifying almost three times the number of obese boys and two times more obese girls than the IOTF. Marrodán et al. ${ }^{(49)}$ also noted that the IOTF criteria tended to underestimate obesity and overestimate overweight. This difference in estimates may possibly be due to the fact that these systems differ in their overall conceptual approach to describing growth ${ }^{(27)}$. They define cut-offs differently and also select samples based on different criteria ${ }^{(12)}$. The IOTF uses age-specific BMI curves that pass through the adult standards for overweight and obesity at age 18 years $\left(25 \mathrm{~kg} / \mathrm{m}^{2}\right.$ and $30 \mathrm{~kg} / \mathrm{m}^{2}$, respectively) and then track backwards to younger ages ${ }^{(26)}$, while the CDC charts represent a growth reference and describe how certain children grew in a particular place and time ${ }^{(27)}$.

The prevalence of obesity via the IOTF criteria was similar to that seen in countries such as Italy, Iran, Canada and Sweden $^{(32,33,50,51)}$. This may suggest that we have caught up with the levels of obesity present in these more industrialized economies ${ }^{(43,44)}$. This early patterning of excess fat among males may increase their risk of chronic disease as adults ${ }^{(52)}$. This is important as over $50 \%$ of all health visits by adults to health facilities in Trinidad and Tobago are due to hypertension and diabetes mellitus ${ }^{(53)}$. For these diseases, overweight and obesity remain important and consistent risk factors $^{(6)}$. Also, children who are overweight and obese are known to track into adulthood ${ }^{(54)}$. Thus the current visits to health facilities for hypertension and diabetes may represent the prevalence of risk factors acquired two to three decades ago, when the prevalences of overweight and obesity were much lower than they are today. These relatively higher levels of adiposity among children suggest that the prevalence of adult diseases in this population will continue to increase in the absence of suitable interventions ${ }^{(43,55)}$. Given the serious implications of these findings for population health, monitoring of overweight and obesity trends beginning in early childhood is recommended ${ }^{(34)}$ and a national surveillance system may be required to follow the development of childhood obesity in different ethnic groups in our population. Intervention programmes should be considered for the school ${ }^{(56)}$ as well as the home setting ${ }^{(57)}$, as these have been shown to be more successful at reducing adiposity and decreasing sedentary behaviours ${ }^{(58)}$.

\section{Etbnic differences in fat patterning}

Ethnicity or race may contribute to the development of childhood obesity ${ }^{(59)}$. In the present study, African children exhibited significantly higher height, weight, BMI, WC and MUAC than their East Indian and Mixed counterparts. People of African descent have greater bone and muscle mass at a given $\mathrm{BMI}^{(60)}$ and this may be reflected as early as age 3 years in our population, especially since there were no significant differences in $\% \mathrm{BF}$ among ethnic groups in our study. The higher weight in African children may possibly be attributed to a greater bone and muscle mass. Although they also presented with a larger BMI, BMI does not differentiate between fat mass and fat-free mass ${ }^{(61)}$. Gulliford et $a l^{(62)}$ (2001) reported similar findings in Trinidad and Tobago with respect to ethnicity, with AfroTrinidadian children being taller than Indo- and Mixed Trinidadians. Several studies have reported a greater adiposity in taller children ${ }^{(63)}$, where taller populations appear to have a higher prevalence of obesity ${ }^{(64)}$. In Indian and Mixed children, BMI values may be biased to lower levels by their lower mean height. In our study, there was a strong positive correlation $(r=0 \cdot 74)$ between weight and height and it has been noted that obese children are considerably taller than their non-obese counterparts $^{(62)}$.

In our study, the CDC criteria classified more African children as being overweight and obese compared with their East Indian and Mixed counterparts $(P<0.001)$. Thus, genetic factors may play an important role in the BMI differences seen in our study ${ }^{(44,65)}$. The higher TSF and BSF observed in the East Indian pre-schoolers may indicate a higher accumulation of body fat in the arms, and suggests a different profile of body fat patterning ${ }^{(62)}$ that may be dependent on ethnic group. Our finding that girls possessed higher TSF than boys was also demonstrated in Iranian children ${ }^{(66)}$. Our data also revealed that WC had an excellent correlation with BMI $(r=0 \cdot 907)$, and it is a highly sensitive and specific measure of truncal adiposity and a strong predictor of visceral adiposity even in the paediatric population. It may also be related to the risks for future metabolic complications and it is therefore crucial to identify and treat children with central adiposity at the earliest possible time ${ }^{(67)}$.

\section{Correlates of adiposity by gender and etbnicity}

BMI, WC, MUAC and TSF remained significant correlates of adiposity in Trinidadian pre-schoolers $(P<0.001)$, even after controlling for age. In pre-school girls, these anthropometric measures may be a simple and quick way of estimating adiposity, as weight and height are quick, cheap and easy to obtain in most research settings. In boys, TSF explained $39 \cdot 2 \%$ of the variance in adiposity. TSF, being conveniently accessible, simple, cheap and quick, is therefore recommended for use among male Trinidadian pre-schoolers. In the ethnic-specific univariate correlates of adiposity, the largest variances were explained by BMI (90.4\%) and WC ( $84.9 \%)$, and this occurred among girls of African descent. The percentage variance in adiposity explained by the various anthropometric measures also tended to be highest for boys of African descent, compared with boys of East Indian or Mixed ancestry. It is possible that the differences observed may have been due to differences in fat distribution among ethnicities. In addition, the body fat locations in pre-schoolers of African descent may have had a stronger association with the 
anthropometric variables of interest in our study. Future longitudinal studies are therefore needed to examine changes in adiposity over time, as well as to unlock the mechanisms that may be involved. Since ethnic differences were evident, it is recommended that ethnicity be factored into any analyses being conducted in this population.

\section{Strengths and limitations}

The most notable strengths of the present study were that schools were randomly selected and all measurements were taken by one trained person, which would have ensured a high degree of consistency. Since the last published study on adiposity in Trinidad was done at least 10 years ago, the present study not only provides timely and relevant information on the current nutritional status of our pre-school children, but also allows for international comparisons with other studies. In addition, we have demonstrated that it is possible to screen for excess adiposity in pre-school Trinidadian children using only age and a single, easily and cheaply obtained anthropometric measurement. In the absence of more sophisticated techniques, our methods may prove beneficial for monitoring in this population. The study's cross-sectional nature does not allow us to gauge changes in adiposity in individual children over time. A longitudinal study design may further improve our understanding of adiposity in this population, especially in males and in children of African descent.

\section{Conclusions}

The present study demonstrates specific differences in adiposity patterning by both ethnicity and gender, with children of African descent exhibiting overall higher anthropometric measurements and pre-school boys being twice as likely as girls to have excess adiposity. While weight, BMI and WC served as excellent correlates of adiposity in females, TSF was the best correlate in males. It may be particularly cost-effective to employ these indices in any research setting, as they are simple, quick, non-invasive and easy to obtain, and - most importantly - convenient and agreeable in this young population.

\section{Acknowledgements}

Sources of funding: This research received no specific grant from any funding agency in the public, commercial or notfor-profit sectors. Conflicts of interest: There are no conflict of interest issues or financial interest issues to be declared. Ethics: The Ministry of Education and the SERVOL Board of Trinidad and Tobago approved the study. Authors' contributions: All authors (A.R.-B., S.N. and N.B.) played a role in the design of the investigation, as well as revision of the many drafts and final manuscript. A.R.-B. was responsible for the recruitment, implementation of field work and preparation of the final manuscript. Statistical analyses were done by S.N. and A.R.-B. Acknowledgements: Special thanks are extended to Salima Ramcharitar and Gregory Bourne for their assistance in recording of measurements during data collection. The authors also wish to thank all participating principals, teachers, parents and pre-school students without whom this research would not have been possible.

\section{References}

1. Chronic Disease Research Centre (2008) Healthy Caribbean 2008 - Caribbean Chronic Disease Conference. CDRC Technical Report Series no. 1. Barbados: Miller Publishing Company.

2. Warraich HJ, Javed F, Faraz-ul-Haq M et al. (2009) Prevalence of obesity in school-going children of Karachi. PLOS ONE 4, e4816.

3. Popkin BM (2001) The nutrition transition and obesity in the developing world. J Nutr 131, issue 3, 871S-873S.

4. Drewnowski A (2007) The real contribution of added sugars and fats to obesity. Epidemiol Rev 29, 160-171.

5. Popkin BM (2004) The nutrition transition: an overview of world patterns of change. Nutr Rev 62, 7 Pt 2, S140-S143.

6. Lloyd LJ, Langley-Evans SC \& McMullen S (2012) Childhood obesity and risk of the adult metabolic syndrome: a systematic review. Int J Obes (Lond) 36, 1-11.

7. Kavey RW, Daniels SR, Lauer RM et al. (2003) American Heart Association guidelines for primary prevention of atherosclerotic cardiovascular disease beginning in childhood. Circulation 107, 1562-1566.

8. Dietz WH \& Robinson TN (2005) Overweight children and adolescents. N Engl J Med 352, 2100-2109.

9. Burns TL, Letuchy EM, Paulos R et al. (2009) Childhood predictors of the metabolic syndrome in middle-aged adults: the Muscatine study. J Pediatr 155, Suppl. 5, e17-e26.

10. Lobstein T, Baur L \& Uauy R (2004) Obesity in children and young people: a crisis in public health. Obes Rev 5, Suppl. $1,4-85$.

11. Martorell R, Kettel Khan L, Hughes ML et al. (2000) Overweight and obesity in preschool children from developing countries. Int J Obes Relat Metab Disord 24, 959-967.

12. Cattaneo A, Monasta L, Stamakis E et al. (2010) Overweight and obesity in infants and pre-school children in the European Union: a review of existing data. Obes Rev 11, 389-398.

13. Martorell R, Khan LK, Hughes ML et al. (1998) Obesity in Latin American women and children. J Nutr 128, 1464-1473.

14. Matheson D, Spranger K \& Saxe A (2002) Preschool children's perceptions of food and their food experiences. $J$ Nutr Educ Behav 34, 85-92.

15. Nightingale CM, Rudnicka AR, Owen et al. (2011) Patterns of body size and adiposity among UK children of South Asian, black African-Caribbean and white European origin: Child Heart and health Study in England (CHASE Study). Int J Epidemiol 40, 33-44.

16. Central Statistical Office (2001) Statistics at a Glance 2001. Port of Spain, Trinidad: Republic of Trinidad and Tobago, Ministry of Planning and Development.

17. Government of the Republic of Trinidad and Tobago, Ministry of Education (2007) Early Childhood Care and Education (ECCE) Schools. http://www.moe.gov.tt/ecc_ directory.html (accessed September 2010).

18. Lee RD \& Nieman DC (2010) Nutritional Assessment, 5th ed., pp. 160-213. New York: The McGraw-Hill Companies, Inc. 
19. Lohman T, Roche A \& Martorell R (editors) (1988) Anthropometric Standardization Reference Manual. Champaign, IL: Human Kinetics Books.

20. Spencer CE, Lingard JM \& Bermingham MA (2003) Comparison of a footpad analyser with a tetrapolar model for the determination of percent body fat in young men. J Sci Med Sport 6, 455-460.

21. Goldfield GS, Cloutier P, Mallory R et al. (2006) Validity of foot-to-foot bioelectrical impedance analysis in overweight and obese children and parents. J Sports Med Phys Fitness 46, 447-453.

22. Jebb SA, Cole TJ, Doman D et al. (2000) Evaluation of the novel Tanita body-fat analyser to measure body composition by comparison with a four-compartment model. BrJ Nutr 83, 115-122.

23. Frisard MI, Greenway FL \& Delany JP (2005) Comparison of methods to assess body composition changes during a period of weight loss. Obes Res 13, 845-854.

24. Hosking J, Metcalf BS, Jeffery AN et al. (2006) Validation of foot-to-foot bioelectrical impedance analysis with dualenergy X-ray absorptiometry in the assessment of body composition in young children: the EarlyBird cohort. $\mathrm{Br} \mathrm{J}$ Nutr 96, 1163-1168.

25. Lazzer S, Boirie Y, Meyer M et al. (2003) Evaluation of two foot-to-foot bioelectrical impedance analysers to assess body composition in overweight and obese adolescents. $\mathrm{Br}$ J Nutr 90, 987-992.

26. Cole TJ, Bellizzi MC, Flegal KM et al. (2000) Establishing a standard definition for child overweight and obesity worldwide: international survey. BMJ 320, 1240-1243.

27. Grummer-Strawn LM, Reinold C \& Krebs NF; Centers for Disease Control and Prevention (2010) Use of World Health Organization and CDC growth charts for children aged 0-59 months in the United States. Morb Mortal Wkly Rep 59, issue RR-9, 1-15.

28. Taylor RW, Jones IE, Williams SM et al. (2002) Body fat percentage measured by dual-energy X-ray absorptiometry corresponding to recently recommended body mass index cutoffs for overweight and obesity in children and adolescents aged 3-18 y. Am J Clin Nutr 76, 1416-1421.

29. Washino K, Takada H, Nagashima M et al. (1999) Significance of the atherosclerogenic index and body fat in children as markers for future, potential coronary heart disease. Pediat Int 41, 260-265.

30. Mei Z, Grummer-Strawn LM, Pietrobelli A et al. (2002) Validity of body mass index compared with other bodycomposition screening indexes for the assessment of body fatness in children and adolescents. Am J Clin Nutr $\mathbf{7 5}$, 978-985.

31. Pietrobelli A, Faith MS, Allison DB et al. (1998) Body mass index as a measure of adiposity among children and adolescents: a validation study. J Pediatr 132, 204-210.

32. Maffeis C, Consolaro A, Cavarzere P et al. (2006) Prevalence of overweight and obesity in 2- to 6-year old Italian children. Obesity (Silver Spring) 14, 765-769.

33. Dorosty AR, Siassi F \& Reilly JJ (2002) Obesity in Iranian children. Arch Dis Child 87, 388-391.

34. Esquivel M \& González C (2010) Excess weight and adiposity in children and adolescents in Havana, Cuba: prevalence and trends, 1972 to 2005. MEDICC Rev 12, 13-18.

35. Monyeki KD, van Lenthe FJ \& Steyn NP (1999) Obesity: does it occur in African children in a rural community in South Africa? Int J Epidemiol 28, 287-292.

36. Dieu HTT, Dibley MJ, Sibbritt D et al. (2007) Prevalence of overweight and obesity in preschool children and associated demographic fectors in Ho Chi Minh City, Vietnam. Int J Pediatr Obes 2, 40-50.

37. World Health Organization (2000) Obesity: Preventing and Managing the Global Epidemic, Report of a WHO Consultation. WHO Technical Report Series no. 894. Geneva: WHO.
38. Reilly JJ (2008) Symposium on 'Behavioural nutrition and energy balance in the young'. Physical activity, sedentary behaviour and energy balance in the preschool child: opportunities for early obesity prevention. Proc Nutr SoC 67, 317-325.

39. Trost SG, Sirard JR, Dowda M et al. (2003) Physical activity in overweight and nonoverweight preschool children. Int J Obes Relat Metab Disord 27, 834-839.

40. Harnack LJ, Jeffrey RW \& Boutelle KN (2002) Temporal trends in energy intake in the United States: an ecologic perspective. Am J Clin Nutr 71, 1478-1484.

41. Due P, Damsgaard MT, Rasmussen M et al. (2009) Socioeconomic position, macroeconomic environment and overweight among adolescents in 35 countries. Int J Obes (Lond) 33, 1084-1093

42. Roskam AJ, Kunst AE, Van Oyen H et al. (2010) Comparative appraisal of educational inequalities in overweight and obesity among adults in 19 European countries. Int J Epidemiol 39, 392-404.

43. Dehghan M, Akhtar-Danesh N \& Merchant AT (2005) Childhood obesity, prevalence and prevention. Nutr J4, 24.

44. Ali AT \& Crowther NJ (2009) Factors predisposing to obesity: a review of the literature. JEMSDA 14, 81-84.

45. Alexis-Thomas C (2010) A sociological analysis of foodconsumption practices of spousal network on eating behaviour of adults with type 2 diabetes in South Trinidad. $\mathrm{PhD}$ Thesis, University of the West Indies.

46. Goldfield GS, Murray MA, Buchholz A et al. (2011) Family meals and body mass index among adolescents: effects of gender. Appl Physiol Nutr Metab 36, 539-546.

47. American Academy of Pediatrics, Committee on Public Education (2001) Children, adolescents, and the television. Pediatrics 107, 423-426.

48. Deurenberg-Yap M, Niti M, Foo LL et al. (2009) Diagnostic accuracy of anthropometric indices for obesity screening among Asian adolescents. Ann Acad Med Singapore 38, 3-6.

49. Marrodán SMD, Mesa Santurino MS, Alba Díaz JA et al. (2006) Obesity screening: updated criteria and their clinical and populational validity. An Pediatr 65, 5-14.

50. Twells LK \& Newhook LA (2011) Obesity prevalence estimates in a Canadian regional population of preschool children using variant growth references. BMC Pediatr 11, 21.

51. Blomquist HK \& Bergström E (2007) Obesity in 4-year old children more prevalent in girls and in municipalities with a low socioeconomic level. Acta Paediatr 96, 113-116.

52. Freedman DS, Khan LK, Serdula MK et al. (2006) Racial and ethnic differences in secular trends for childhood BMI, weight and height. Obesity (Silver Spring) 14, 301-308.

53. Nichols SD \& Crichlow H (2010) An evaluation of the diagnostic utility of anthropometric and body composition cut-off values in assessing elevated fasting blood sugar and blood pressure. West Indian Med J 59, 253-258.

54. Singh AS, Mulder C, Twisk JW et al. (2008) Tracking of childhood overweight into adulthood: a systematic review of the literature. Obes Rev 9, 474-488.

55. Gaskin PS \& Walker SP (2003) Obesity in a cohort of black Jamaican children as estimated by BMI and other indices of adiposity. Eur J Clin Nutr 57, 420-426.

56. Freia DB, Breitenstein L \& Fischer JE (2012) Positive impact of a pre-school-based nutritional intervention on children's fruit and vegetable intake: results of a cluster-randomized trial. Public Health Nutr 15, 466-475.

57. Briggs L \& Lake AA (2011) Exploring school and home food environments: perceptions of 8-10-year-olds and their parents in Newcastle upon Tyne, UK. Public Health Nutr 14, 2227-2235.

58. Summerbell CD, Moore HJ, Vögele C et al. (2012) Evidence-based recommendations for the development of 
obesity prevention programs targeted at preschool children. Obes Rev 13, Suppl. 1, 129-132.

59. Hernandez B, Uphold CR, Graham MV et al. (1998) Prevalence and correlates of obesity in preschool children. J Pediatr Nurs 13, 68-76.

60. Wagner DR \& Heyward VH (2000) Measures of body composition in blacks and whites: a comparative review. Am J Clin Nutr 71, 1387-1389.

61. Sweeting HN (2007) Measurement and definitions of obesity in childhood and adolescence: a field guide for the uninitiated. Nutr $J \mathbf{6}, 32$.

62. Gulliford MC, Mahabir D, Rocke B et al. (2001) Overweight, obesity and skinfold thicknesses of children of African or Indian descent in Trinidad and Tobago. Int $J$ Epidemiol 30, 989-998.
63. Freedman DS, Thornton JC, Mei Z et al. (2004) Height and adiposity among children. Obes Res 12, 846-853.

64. Franklin MF (1999) Comparison of weight and height relations in boys from 4 countries. Am J Clin Nutr 70, issue 1, 157S-162S.

65. Bouchard C (2009) Childhood obesity: are genetic differences involved? Am J Clin Nutr 89, issue 5, 1494S-1501S.

66. Ayatollahi S-M-T \& Mostajabi F (2008) Triceps skinfold thickness centile charts in primary school children in Shiraz, Iran. Arch Iranian Med 11, 210-213.

67. Mazicioğlu MM, Hatipoğlu N, Öztürk A et al. (2010) Waist circumference and mid-upper arm circumference in evaluation of obesity in children aged between 6 and 17 years. J Clin Res Pediatr Endocrinol 2, 144-150. 